\title{
Common Factors in Psychotherapy: The Autonomic Nervous System Final Common Pathway
}

\author{
Joachim Fana Lance Mureriwa* \\ Clinical Practice, Louis Pasteur Hospital (Medical Suites), 380 Francis Baard Street, Pretoria, South Africa \\ *Corresponding author: Joachim Fana Lance Mureriwa, Clinical Practice, Room 26 Louis Pasteur Medical \\ Suites, 380 Francis Baard Street, Pretoria, South Africa, Tel: +27 825747145; Fax: +27 124302642; E-mail: \\ drmureriwa@biofeedback.co.za
}

Received Date: 07 September, 2017; Accepted Date: 13 November, 2017; Published Date: 28 November, 2017

\begin{abstract}
The practice of psychotherapy is characterized by allegiance to different schools of thought, mainly psychodynamic therapies, behaviour therapies, cognitive behaviour therapies, humanistic therapies, and integrative therapies. Proponents of these schools of thought propose that psychotherapies are effective because of therapeutic factors specific to their perspective. From about the late 1930's however, there has been growing consensus that the different forms of psychotherapy are equally effective. This lack of superiority of one form of psychotherapy over others is argued to be because of psychotherapy factors which are common across the different schools of thought. The most frequently cited factors are events happening outside therapy, the nature of the therapist-client relationship, the placebo effect, and, the specific psychotherapy techniques used. In this paper, I propose that the Autonomic Nervous System (ANS), rather than these common factors, is the final common pathway for psychotherapy outcome. The implications for the practice of psychotherapy are discussed.
\end{abstract}

\section{Keywords}

Autonomic Nervous System (ANS); Applied Psychophysiology; Biofeedback; Common Factors; Limbic System; Parasympathetic Nervous System; Psychotherapy

\section{Background}

\section{Specific and common factors in psychotherapy}

Specific factors in psychotherapy: The practice of psychotherapy is guided by five main approaches, namely psychodynamic therapies, behaviour therapies, cognitive behaviour therapies, humanistic therapies, and integrative therapies. These approaches attempt to provide theoretical frameworks for the origins of mental disorders and they propose treatment strategies based on those frameworks. The various school of thought have together given rise to over 1,000 specific treatment techniques [1]. In table 1 below, the five schools of thought in psychotherapy are listed, together with pathogenesis, goals of treatment, and sample techniques.

Adherents of the different schools of thought propose that the success of psychotherapy depends on the specific factors inherent in their models. In other words, treatment success depends mostly on resolution of subconscious conflicts, learning processes, alteration of thinking patterns, the therapeutic relationship, and other factors.

Attempts have been made to identify the treatments of choice for different psychological conditions. The UK Department of Health [3] for example, published guidelines for the psychological treatment of several psychological disorders, and medical disorders, such as pre-menstrual syndrome. For depression, they concluded that evidence suggested that Cognitive Behaviour Therapy and interpersonal therapy were efficacious, but Cognitive Behaviour Therapy was most efficacious. The assumption on which the guidelines are based is that psychotherapy techniques differ in the extent to which they are effective for different conditions.

The effort to identify the specific treatments and techniques for specific psychological disorders continues to the present. It has been argued for example, that exposure and response prevention are the psychological treatments of choice for Obsessive-Compulsive Disorder (OCD) and should be first line treatments [4].

Common factors in psychotherapy: Rosenzweig [5] is credited with first proposing that psychotherapies from the different schools of thought are equally effective for all conditions. He argued that the therapies are equally effective because they share the following common factors. 
Citation: Mureriwa JFL (2017) Common Factors in Psychotherapy: The Autonomic Nervous System Final Common Pathway. Curr Adv Neurol Neurol Disord 2017: 1-12. DOI : https://doi.org/10.29199/2637-6997/CANN-101016.

\begin{tabular}{|c|l|l|l|}
\hline School of Thought & Sources of Psychological Disorder & \multicolumn{1}{|c|}{ Goals of Therapy } & $\begin{array}{l}\text { Sample } \\
\text { Techniques }\end{array}$ \\
\hline Psychodynamic & $\begin{array}{l}\text { Unconscious processes, such as de- } \\
\text { fence mechanisms. }\end{array}$ & $\begin{array}{l}\text { Uncovering unconscious. processes- working } \\
\text { through the processes. }\end{array}$ & $\begin{array}{l}\text { Dream analysis. } \\
\text { Hypnotherapy. }\end{array}$ \\
\hline Behaviour Therapies & $\begin{array}{l}\text { Faulty learning: Relationships be- } \\
\text { tween behaviour and consequences. }\end{array}$ & $\begin{array}{l}\text { Reverse faulty learning. Learning more adap- } \\
\text { tive behaviours. }\end{array}$ & $\begin{array}{l}\text { Systematic desensiti- } \\
\text { zation. }\end{array}$ \\
\hline Cognitive Therapies & $\begin{array}{l}\text { Emotional and behavioural prob- } \\
\text { lems are a result of faulty thinking } \\
\text { patterns. }\end{array}$ & $\begin{array}{l}\text { Retraining thinking patterns to alter emotions } \\
\text { and behaviour in a more adaptive direction. }\end{array}$ & $\begin{array}{l}\text { Cognitive Behaviour } \\
\text { Therapy (CBT). }\end{array}$ \\
\hline Humanistic Therapies & $\begin{array}{l}\text { Humans are self-aware, self-actual- } \\
\text { izing and have the capacity to heal } \\
\text { themselves. }\end{array}$ & $\begin{array}{l}\text { According to Rogers [2], therapy should aim } \\
\text { to provide the necessary and sufficient con- } \\
\text { ditions for self-actualization and healing. } \\
\text { The conditions in therapy include empathy, } \\
\text { warmth, and unconditional positive regard. }\end{array}$ & $\begin{array}{l}\text { Client-centred } \\
\text { chotherapy. }\end{array}$ \\
\hline Integrative Therapies & $\begin{array}{l}\text { Psychological disorders can arise } \\
\text { from factors described by any of the } \\
\text { foregoing schools of thought. }\end{array}$ & $\begin{array}{l}\text { Systematic application of techniques from } \\
\text { various schools of thought, based on the } \\
\text { needs of the patient. }\end{array}$ & $\begin{array}{l}\text { Systematic } \\
\text { nation of techniques } \\
\text { from various school of } \\
\text { thought. }\end{array}$ \\
\hline
\end{tabular}

Table 1: Schools of Thought with Abbreviated Rationale and Intervention Approaches.

a. The operation of implicit, unverbalized factors, such as carthasis, and the yet undefined effect of the personality of the good therapist.

b. The formal consistency of the therapeutic ideology as a basis for re-integration, and

c. The alternative formulation of psychological events and the interdependence of personality organization.

According to Rosenzweig [5], common factors such as these "reduce the effectual importance of mooted differences between one form of psychotherapy and another" (p. 415).

Jerome Frank [6] proposed that all successful therapies have the following factors in common: client expectation of help, the therapeutic relationship, a rational explanation of the cause of the symptoms, with a prescription of the rituals or procedure for treatment, and the participation of the therapist and client to achieve the treatment goals.

Following the pioneering work of Rosenzweig [5], Frank [6], Luborsky and Luborsky [7] and other early investigators, numerous lists of common factors were proposed. In a very influential meta-analytic study Lambert [8] identified 4 sets of common factors, and estimated the percentage contribution of each of these factors to successful psychotherapy.

\begin{tabular}{|c|c|}
\hline Common Factors & $\mathbf{\%}$ \\
\hline Extra-therapeutic factors & 40 \\
\hline Relationship factors & 30 \\
\hline Placebo, hope, expectancy & 15 \\
\hline Therapy technique & 15 \\
\hline
\end{tabular}

Table 1: Common factors as described by Lambert [8].
Extra-therapeutic factors: These are the individual's personal attributes, such as the personality, previous life experiences, current life circumstances, health status, hereditary factors, and any other personal characteristic that can negatively or positively impact the outcome of psychotherapy.

Relationship factors: According to Rogers [2], an optimal relationship, on the part of the therapist, is characterized by empathy, warmth, and unconditional positive regard (acceptance). He proposed that when the subject comes to consult, they will be in a state of "incongruence", which is the motivation for seeking therapy. For effective therapy, the therapist should communicate to the client, that he/she is empathic, warm, and accepting. The therapist should communicate congruency (genuineness). Empathy is the therapist's perceived desire and capacity to understand the world from the client's perspective.

Wampold [9] proposed a contextual model comprised of three pathways, a) the real relationship, b) the creation of expectations through explanation of disorder and the treatment involved, and c) the enactment of health promoting actions. Before these pathways can be activated, an initial therapeutic relationship must be established.

The Placebo, hope, and expectancy: Some patients with physical ailments feel better, even when administered inert substances such as sugar pills, if they are informed that they are receiving real medication. This is the placebo effect. It is proposed that some patients improve in psychotherapy by such placebo effects. People enter therapy with the hope that they will be successfully treated, and the expectation that this will happen.

Therapy technique: These are the specific techniques of psychotherapy which have been developed in the context of the various schools of thought over the years. Some of these are listed in table 1 above. 
Concluding comment on common factors: The proposals of Rosenzweig [5], Frank [6], and others, supported by meta-studies such as Lambert [8] have led to a growing acceptance that there is no significant difference in effectiveness between the different types of psychotherapy. Instead, research continues to identify the common factors which contribute to good outcome in psychotherapy. The proposal in this paper is that the common factors are not the ultimate explanation for why therapy works. Rather, these factors all converge on biological final common pathways, mainly the Autonomic Nervous System. The common factors contribute to effective psychotherapy only to the extent that they bring about biological effects, just as the medicines do. As a prelude to the discussion of a final common pathway in psychotherapy, I provide a brief overview of the Autonomic Nervous System below.

\section{The Autonomic Nervous System (ANS)}

\section{The ANS and unconscious processes}

The Autonomic Nervous System, together with the somatic nervous system, make up the peripheral nervous system. These systems are peripheral to the Central Nervous System (CNS), which comprises of the brain and the spinal cord. The somatic nervous system relays sensory information from the organs to the Central Nervous System, and relays motor commands from the Central Nervous System to the periphery.

The Autonomic Nervous System, on the other hand, controls processes which do not require conscious awareness, such as heart rate, digestion, and a myriad of other processes. Without the person's conscious awareness or intention, the Autonomic Nervous System adjusts the body to changes in the environment. For example, when one walks into a dark place the pupils dilate, and on walking into a bright environment the pupils constrict. Cold weather leads to shivering, whilst hot whether leads to sweating. Autonomic responses such as these (pupil dilation, shivering, and others), can also be triggered by emotional stimuli. It is worth noting however, that the Autonomic Nervous System is not alone in controlling body processes below the level of awareness. We maintain appropriate body posture and muscle tone, for example, without conscious effort, because of the actions of the cerebellum, basal ganglia, and other structures.

The Autonomic Nervous System has two divisions, the Sympathetic Nervous System and the Parasympathetic Nervous System.

\section{The Sympathetic Nervous System (SNS)}

When an individual is confronted with danger, or any form of stress, the SNS brings about the well-known "fight or flight" responses, by releasing neurotransmitters and stress hormones, such as norepinephrine, epinephrine, and cortisol. The physiological changes include both stimulation and inhibition. Fear, for example, stress brings about increased heart rate and breathing rate, but inhibits digestive processes. Both acute and chronic stress can disrupt sleep, by increasing or decreasing sleep. The SNS leads to energy expenditure: More oxygen is consumed, glycogen is broken down into glucose, and heat is produced, as the muscles tense up and work. At the end of intense SNS activity, the body is in need of rest and repair. It is notable that many of the medications used in psychiatry are prescribed to reduce the levels of some many stress chemicals, particularly epinephrine and norepinephrine. I propose that psychotherapy does the same. On the other hand, when patients are under-aroused (depression, attention deficits), the need is not to reduce these neurotransmitters, but to increase them. With respect to psychotherapy, I propose that there are many arousing techniques, perhaps including carthasis and modulation of thought patterns, as happens in CBT.

\section{The Parasympathetic Nervous System (PNS)}

The PNS generally bring about physiological changes opposite to those of the SNS. It is predominant during periods of reduced stress, and is associated with reduced energy expenditure, as evidenced by, for example, reduced heart rate, muscle relaxation, reduced breathing rate, decreased mental focus, digestion, excretion, and even sleep. PNS activity conserves energy and restores the body to a restful state. The predominant neurotransmitter is acetylcholine. I propose that just as the psychotropic medicines do, psychotherapy, for some conditions, is effective because it increases parasympathetic activity. Therapy techniques such as relaxation training, breathing exercises, and others, are, in reality, techniques for modulating the Autonomic System, by toning down the SNS and enhancing the PNS.

\section{The Autonomic Nervous System and the Hypothal- amus}

The Autonomic System originates in the Hypothalamus, and descends to the periphery, where it exercises diffuse influence on multiple body systems and organs:

Fibers for the Sympathetic Nervous System originate from the Posterior Hypothalamus, and descend via the Hypothalamo-spinal Pathway to the thoracic and lumbar regions of the spinal cord (T1 to L2 or 3). They exit the spinal cord to innervate multiple organs, and they are the means by which the fight or flight responses are produced.

The Parasympathetic Nervous System originates from the Anterior Hypothalamus and descends via the dorsal longitudinal fasciculus. Along the way, the parasympathetic fibers innervate the cranial nerve nuclei III, VII, IX, and X; as well as the parasympathetic outflow of the sacral region $\mathrm{S} 2, \mathrm{~S} 3$, and $\mathrm{S} 4$.

\section{Hypothalamic connections}

Because the ANS originates from the Hypothalamus, it is subject to influence by the connections which the Hypothalamus has with other structures in the nervous system. This is especially so for the links between the Hypothalamus and the limbic system. In table 3 below is a list of some of the connections of the Hypothalamus. 
Citation: Mureriwa JFL (2017) Common Factors in Psychotherapy: The Autonomic Nervous System Final Common Pathway. Curr Adv Neurol Neurol Disord 2017: 1-12.

\begin{tabular}{|c|c|c|}
\hline Structure & Pathways & Related Psychological Processes \\
\hline $\begin{array}{l}\text { Hoppocampal Formation } \\
\text { (Medial Temporal Lobes) }\end{array}$ & Fornix & $\begin{array}{l}\text { Recent memory. } \\
\text { Through links with the amygdala, forms episodic rep- } \\
\text { resentations of the emotional significance and interpreta- } \\
\text { tion of events [10]. }\end{array}$ \\
\hline Amygdala (Medial Temporal Lobes) & $\begin{array}{l}\text { Stria terminalis. } \\
\text { Ventral amygdalofugal pathway. }\end{array}$ & $\begin{array}{l}\text { Emotions: Sex and aggression. } \\
\text { Links with hippocampus to provide emotional valence to } \\
\text { memories [10]. }\end{array}$ \\
\hline Thalamus & $\begin{array}{l}\text { Mammilothalamic tract. } \\
\text { Inferior thalamic peduncle. }\end{array}$ & $\begin{array}{l}\text { Thalamus is the gateway for sensory inputs except for ol- } \\
\text { factory. } \\
\text { The thalamus is responsible for cortical arousal. } \\
\text { Projections to the cingulate cortex: emotion formation, } \\
\text { learning, and memory. }\end{array}$ \\
\hline Cingulate & Inferior thalamic peduncle. & Emotions, learning, and memory. \\
\hline Orbitofrontal lobe & Medial Forebrain Bundle & $\begin{array}{l}\text { The orbitofrontal lobes are important for behavioural control } \\
\text { and inhibition. }\end{array}$ \\
\hline Olfactory Bulb & Medial Forebrain Bundle. & Sense of smell. Strong links with memory [11]. \\
\hline Septal Nucleus & Medial Forebrain Bundle & Plays a role in reward and punishment [12]. \\
\hline $\begin{array}{l}\text { Pituitary Gland (Anterior and Pos- } \\
\text { terior) }\end{array}$ & $\begin{array}{l}\text { Supraoptico hypophyseal. } \\
\text { Tubero hypophyseal. }\end{array}$ & Activation/ inhibition of hormone production. \\
\hline $\begin{array}{l}\text { Dorsal tegmental area, ventral teg- } \\
\text { mental nuclei, and nucleus raphe. }\end{array}$ & $\begin{array}{l}\text { Hypothalamus to nuclei: mammilloteg- } \\
\text { mental pathway. } \\
\text { Nuclei to Hypothalamus: Mammillary } \\
\text { peduncle. }\end{array}$ & $\begin{array}{l}\text { Ventral tegmental area: origin of dopamine pathways (Re- } \\
\text { ward, motivation, cognition, addictions). } \\
\text { Dorsal Tegmental nuclei: Production of acetylcholine, a } \\
\text { mainly excitatory neurotransmitter (also inhibitory). } \\
\text { Nucleus Raphe: Serotonin production: Levels of serotonin } \\
\text { are linked to mental disorders, including depression. }\end{array}$ \\
\hline
\end{tabular}

Table 3: Hypothalamic Connections with a bearing on the ANS.

[NB: The structures cited below not only link with the Hypothalamus, but extensively link with each other].

The Autonomic Nervous System as a common factor in emotional disorders

In summary, the Sympathetic Nervous System responses of fight or flight, and the restful states associated with the Parasympathetic Nervous System, arise from the Hypothalamus. The Hypothalamus, in turn, has numerous connections with the limbic system and the cerebral cortex. For the rest of this paper, I discuss the proposal that the effectiveness of different psychotherapy techniques is primarily attributable to one usually unacknowledged final common factor, the modulation of the Autonomic Nervous System.

\section{Neurobiology of Psychotherapy}

\section{Scope of the brief review of neurobiology of psycho- therapy}

A complete and detailed review of the neurobiology of psycho- therapy is beyond the scope of this paper. The aim, rather, is to draw attention to empirical research and reviews which demonstrate that psychotherapy gives rise to measurable biological change. It is proposed that these biological changes converge on the Autonomic Nervous System.

\section{Brief review}

Early humans considered psychological disorders, or mental illnesses, to be spiritual or demonic phenomena. The Greek physician Hippocrates is often credited with being the first to formally propose that mental disorders were medical diseases. At the time that Sigmund Freud [13] introduced psychoanalysis, the biological mechanisms underlying psychotherapy were unknown. He believed, however, that in due course, these mechanisms would be discovered.

\section{Pharmacotherapy vs psychotherapy}

The discovery, sometimes serendipitously, of the effectiveness 
of medications, such as chlorpromazine in the $1950 \mathrm{~s}$, provided a boost to the view that psychological disorders had biological origins, especially imbalances of neurotransmitters. Most of the treatments developed since then focus on modulating neuro-transmitter levels of epinephrine, norepinephrine, dopamine, acetylcholine, acetylcholine, serotonin, and others. Drugs of abuse, such as the amphetamines, target the same neurotransmitter systems.

Psychotropic medication and psychotherapy have always been used side by side for the management of psychological disorders. The mechanism of action of the psychiatric medication, even if not fully understood, are accepted as biological. On the other hand, the mechanisms of action for psychotherapy are often considered as non-biological. These non-biological factors include the specific therapeutic factors discussed above, such retraining thinking patterns (CBT); or the operation of common factors, namely extra-therapeutic factors, relationship factors, expectancy, and specific therapy techniques. At face value, pharmacotherapy and psychotherapy appear to be vastly different interventions, one being biological, and the other supposedly non-biological. In this paper, an attempt is made to show that both approaches are biological, and owe their effectiveness largely to a common factor, the modulation of the Autonomic Nervous System activity.

\section{The biology of psychological processes}

The assumption that the psychological mechanisms operative in psychotherapy are non-biological runs contrary to established knowledge in psychology, or at least the disciplines known as physiological psychology and neuropsychology.

All psychological processes, from the most basic/ elementary, to the most complex are based on activities in the nervous system, as briefly illustrated in table 4 below.

\section{Biological effects of psychotherapy}

If psychological processes are biologically based, all effective interventions, including psychotherapy, should involve biological mechanisms.

Taking into account findings from meta-analytic studies, Etkin [16] stated that there is no longer any doubt that psychotherapy can result in detectable changes in the brain (p.155). Numerous neuro-imaging studies $[17,18]$ have identified some of the biological changes associated with psychotherapy: changes in basal metabolic rates or basal cerebral flow to specific brain, including the dorsolateral prefrontal cortex, ventrolateral prefrontal cortex, the amygdala, cingulate, hippocampus, basal ganglia, the thyroid axis, and others.

The idea of mirror neurons first described by Di Pellegrino, Fadiga, Fogassi, Gallese, and Rizzolatti [17] and later by Rizzolatti and Craighero [18] provide clues to the physiological mechanisms underlying empathy. Silani, Lamm, Ruff, and Singer [19], for example, showed that brain networks involving the right supramarginal gyrus are involved in empathy.

\begin{tabular}{|c|c|}
\hline Psychological Process & Some Associated Nervous System Structures/ Systems \\
\hline Arousal/ alertness & Reticular activating system \\
\hline Sensation & $\begin{array}{l}\text { Receptors on special senses: vision, hearing, taste, touch, and smell; other senses, e.g. } \\
\text { sense of position. }\end{array}$ \\
\hline Perception & $\begin{array}{l}\text { Built on sensation. Involves all lobes of the brain-occipital, parietal, temporal, and } \\
\text { frontal. }\end{array}$ \\
\hline Emotions, motivation, basic needs & Limbic system \\
\hline $\begin{array}{l}\text { Cognitive processes: attention, memory, intelli- } \\
\text { gence, language, abstract thinking, and others }\end{array}$ & $\begin{array}{l}\text { Brain networks involving all the lobes of the brain (occipital, parietal, temporal, and } \\
\text { frontal); limbic structures, including the cingulate and hippocampus. }\end{array}$ \\
\hline $\begin{array}{l}\text { Executive functions (goal-setting, planning, } \\
\text { self-control, self-monitoring etc). }\end{array}$ & Frontal lobes in association with all other brain areas. \\
\hline All Psychological Processes & $\begin{array}{l}\text { Luria [14]: Psychological functions are not localized to individual brain structures. They } \\
\text { are based on hierarchically organized functional units. } \\
\text { - First functional unit: For cortical arousal and wakefulness; includes reticular } \\
\text { formation, limbic system, and aspects of the forebrain. } \\
\text { - Second functional unit: For receiving, analysing and storing information; occipital, } \\
\text { temporal, and parietal lobes. } \\
\text { - Third functional unit: frontal lobes; executive functions. } \\
\text { - Current thinking on brain function emphasizes brain networks, rather than individual } \\
\text { brain structures. Raichle [15] identified the Default Mode Network, and networks } \\
\text { for somatosensory, control, auditory, and visual functions. }\end{array}$ \\
\hline
\end{tabular}

Table 4: Biological Foundations of Psychological Processes. 
Liggan and Kay [20] compared neurobiological changes associated with different schools of thought. Treatments based on the behavioural school, particularly lead to changes in the amygdala, basal ganglia, and hippocampus. Cognitive therapy, which focusses on information processing, focuses on specific patterns of information processing which mainly involve the neocortex, especially the frontal lobes. Brooks [21] reviewed the literature and concluded that CBT helps the prefrontal cortex to control the subcortical structures. Boccia and colleagues [22] found that for depression, psychotherapy specifically induces selective modifications in the left inferior and superior frontal gyri, middle temporal gyrus, lingual gyrus and middle cingulate cortex, as well as in the right middle frontal gyrus and precentral gyrus. On the other hand, drug therapy selectively affected brain activation in the right insula. Kalsi et al., [23] found that patients undergoing psychotherapy showed an increase in the right paracingulate activity, while pharmacological treatment led to a decrease of activation of this area.

The biological effects of psychotherapy and pharmacological treatment are not necessarily identical, but are often complimentary. In other words, even though both interventions lead to biological change, they may do so through different brain structures and/or systems.

Many of the structures cited as associated with psychotherapy outcome are part of the limbic system, the main brain region involved in emotional responses. As Levenson [24] stated, "When it comes to emotion, all roads lead to the Autonomic Nervous System (ANS). Whether it is the generation, expression, experience, or recognition of emotion, the role of the ANS is critical" (p.100). The limbic system activates the Autonomic System, allowing the subject and other observers to observe some of the physiological effects of the emotion.

\section{The Autonomic Nervous System as a Fi- nal Common Pathway in Psychotherapy}

In the sections which follow, an attempt is made to illustrate why, taking the common factors approach into account, the ANS should be considered as a final common pathway in psychotherapy. The common outcome is an optimal balance between sympathetic and parasympathetic. In discussing common factors, I will make reference to Lambert's [8] list of common psychotherapy factors.

\section{The ANS and the extra-therapeutic factors}

The meta-analytic studies estimate that $40 \%$ of the variance of psychotherapy outcome is from extra-therapeutic factors. The author is of the view that if extra-therapeutic factors have an effect on outcome, it means that they have a strong emotional impact. In other words, extra-therapeutic factors are relevant to psychotherapy because they are sources of stress. These factors are equally important as sources of factors which moderate the negative impact of stress.
It is notable that Selye [25], a major contributor to our understanding of the stress phenomenon, defined stress as the non-specific response of the body to any demand for change. He described the General Adaptation Syndrome (GAS), which is comprised of 3 stages: alarm, resistance, and exhaustion. In the alarm stage, the body mounts Sympathetic Nervous System responses to combat the stress. The second stage is resistance, where the body increases parasympathetic responses to counter the excesses of the Sympathetic Nervous System. Finally, in the exhaustion stage, the body's resources for resisting stress are exhausted, and illness ensues.

The "extra-therapeutic factors" are the events which bring clients to therapy in the first place. Therapy is only commenced because the client presents with a problem. Rogers [2] explicitly stated that when clients come to therapy, they are in a state of stress, which he labeled as a state of "incongruence". Taking this into account, the positive and negative impact of extra-therapeutic events on the psychological status of a patient should not be surprising. Rather, a worthwhile strategy in psychotherapy would be to train patients to learn self-modulation as part of self-improvement, and as preparation for coping with current and future stress.

My proposal is that the extra-therapeutic factors and the therapy techniques should not be classified together as "common factors". Rather, the extra-therapeutic factors exert the stress, and therapy provides the means for coping with the stress. In some instances, the extra-therapeutic events can be so overwhelming that they nullify the efforts of the therapist and the patient. However, equally so, the therapeutic strategies may be so powerful that the patient manages to maintain a state of calm and adjustment (parasympathetic), despite overwhelming stress. In a sense, entering into therapy is just one instance, in a life-long series of positive and negative events. The experience with one therapist will, in due course, be part of what the patient will take to the next therapist. In other words, today's in-therapy experience the patient, is an "extra-therapeutic" factor for another future therapist.

\section{The ANS and relationship factors}

The humanistic approach to psychotherapy, especially the approach by Carl Rogers [2], emphasized the importance of therapist empathy. According to this approach, humans have an innate (i.e., biological) need for empathy. There is ongoing research on the neural basis of empathy [26,27]. The structures involved with empathic responses include the cingulate, insula, amygdala, and supramarginal gyrus; and the research is ongoing.

If, as indicated by meta-analytic studies, the empathic relationships are effective factors in psychotherapy, they should modulate activities in the Autonomic Nervous System, just as medications do. This highlights the importance for psychotherapists, psychologists included, to monitor the Autonomic Nervous System, using psychophysiological equipment and the assessment of vital signs. 


\section{Placebo, hope, and expectancy}

A placebo is a pharmacologically innate substance or procedure that leads to a relief of symptoms. It is considered as "just psychological", because symptom relief is the result of the patient's expectation of cure, and not the result of a bona fide physical intervention. It is now known, however, that a placebo is actually a chemical event like any other drug treatment. Esch and Stefano [28] reviewed the literature and concluded that the placebo effect is mediated by dopaminergic - and possibly morphinergic - reward mechanisms. The placebo response relies on trust and belief, and this connection has its neurobiological roots predominantly in limbic or frontal/prefrontal brain activity.

\section{Therapy technique}

Establishing rapport (All therapies): The need for establishing good rapport with a patient is a universally accepted necessary first step in medical practice and for psychotherapy, whatever school of thought the therapist ascribes to. Indeed, all service providers, and not just health practitioners, aim to establish good rapport with their customers: salespersons, attorneys, teachers, bankers, negotiators, and others, try to be friendly and reassuring. They offer comfortable seats and drinks, and often explicitly invite the customers to make themselves comfortable. Apart from ensuring that the customers are comfortable, non-clinical service providers, just like the clinicians, do whatever they can to reassure clients that they are knowledgeable, efficient, and trustworthy.

It is clear that the building of rapport contributes to a sense of relaxation and calmness. The importance of rapport-building is applicable across all forms of psychotherapy. The humanistic approach to psychotherapy especially emphasizes the importance of good rapport building, and, as Rogers [2] indicated, it is a way to reduce the aversive experience of incongruence. Such experience is underpinned by the excesses or deficits of the Autonomic Nervous System.

Conditioning responses (Behaviour therapies): Although it is often not explicitly stated, behavioural interventions such as systematic desensitization produces positive therapeutic outcome because they dampen the excesses of the Sympathetic Nervous System (epinephrine/ norepinephrine), and enhance parasympathetic activity. These interventions address the emotions of fear and anxiety, typically associated with increased heart rate, dysfunctional breathing pattern, sweating, dry mouth, trembling and others. In the presence of a feared stimuli, behaviour therapy replaces a dysfunctional response (excess sympathetic) with a functional one (parasympathetic).

Relaxation therapy, a frequently used procedure in behaviour therapy is directly enhancing the "relaxation response", which, in essence, is a Parasympathetic Nervous System response.

Modifying dysfunctional thoughts (Cognitive therapies): A major principle of Cognitive Behavior Therapy (CBT) $[29,30]$ is that negative emotions arise from dysfunctional thoughts about events. Ellis describes this as an ABC Model (Activating events, beliefs, and consequences).

The ABC model provides a clue about the underlying neurophysiology, which involves the entire brain. First there are activating events, which necessarily involves the brain's arousal systems. Luria [14] described this function of the brain as his first function unit of the brain. It involves the reticular activating system, arouses the entire brain, and of special importance to this paper, it arouses the limbic system. Second, Luria's [14] second functional unit is responsible for the reception, analysis, and storage of information. It involves the occipital, temporal, parietal, and frontal lobes. These brain structures, together with the limbic system, have neural systems which maintain the person's memories and beliefs, relating to the activating events. The consequences are the emotional reactions, which are tied to the activities of the limbic system. Finally, the emotional processes express themselves either as fight or flight responses, which may be mild, moderate, or severe.

Neuro-imaging studies suggest that both CBT and drug therapies modulate the cortico-limbic pathways, but in complimentary, rather than identical ways [31,32]. It appears that CBT in some way involves excitatory and inhibitory processes between the frontal cortex and the limbic system [33]. In other words, the frontal lobes (thoughts and beliefs), probably send inhibitory messages to the limbic system, to reduce the activities of the Sympathetic Nervous System.

Working with subconscious processes (psychoanalysis): Psychoanalysis emphasizes subconscious processes in the early development of personality and in subsequent interpersonal relationships and other experiences. The aim of therapy, in part, is to resolve the unconscious processes and conflicts which affect conscious behaviour. Carthasis is the expression of the negative emotions associated with a past event. Psychoanalysis, and other therapies appear to provide a means by which the subject can finally shift from sympathetic over-arousal to a state of relaxation (parasympathetic).

In a review that focussed on schizophrenia, Salone et al., [34] concluded as follows: The CMS (Cortical Midline Structures) and their networks (right posterior insula, right inferior parietal cortex, ventromedial prefrontal cortex) may represent neural correlates of the "core self" and [2]; Ego functioning most likely corresponds to the activation of the DMN (Default Mode Network) and its reciprocal exchanges with other brain networks. An altered functional connectivity between cortical and limbic nodes of the DMN may predict symptoms of ego disturbance, such as alterations of primary process thinking in schizophrenia or attribution of negative emotions to the self in depressive disorders.

Studies such as these point to the likelihood that in years to come, much will be discovered with regards to the neurobiological basis of psychodynamic therapies. I note for example, there 
is a push by leading psychoanalysts, to bring psychoanalysis and the neurosciences closer together [35].

In line with the aims of this paper, it is notable that psychoanalysis points to subconscious conflicts as a source of psychological disorders. "Conflicts" necessarily imply tension and stress, and thus must be related in some way to the limbic system and the Autonomic Nervous System.

The functions of the Autonomic Nervous System are involuntary, and thus unconscious. It remains to be debated whether or not this "unconsciousness" is the same type as the psychoanalytic concept. What is clear is that any well-learned skill, such as the mechanical aspects of driving a car, do not require conscious decision-making and awareness. The basal ganglia and the cerebellum control many of our motor actions without conscious awareness.

Pally [36] discussed the role of non-verbal communication in psychotherapy, and stated that the impact of nonverbal cues is mediated by circuits involving limbic structures in the brain. These circuits activate nonverbal cues along with changes in hormone levels, neurotransmitters and the Autonomic Nervous System.

\section{Practical Applications}

The assumption that the ANS is the final common pathway in psychotherapy has the potential to contribute to psychotherapy integration. It would call for therapists to adopt some common explanatory concepts and procedures. At the same time, the therapists would largely still be able to largely practice within their favored school of thought. The additional concepts and procedures are listed below. I attempt to link the concepts and procedures to the sets of common factors quoted earlier, i.e., extra-therapeutic factors, relationship factors, placebo, and techniques.

\section{Vital signs assessment}

Vital signs (temperature, pulse, respiration, and $\mathrm{BP}$ ) provide important information about the Autonomic Nervous System. Psychiatrists and psychologists, but especially psychologists, do not typically assess vital signs, leaving that to other health workers. There is a need to sensitize all health practitioners, that any chronic illness which a client has, and which vital signs can help to identify, is a potent source of psychological stress. It requires as much attention by the psychologists, as any other stressful life events described by the patient.

\section{Applied psychophysiology assessment}

Despite the fact that during training, psychologists take courses in physiological psychology and biological psychology, this knowledge is rarely applied in practice. It is a readily available method for monitoring the Autonomic Nervous System.
Using this technology, psychologists can perform "Physiological Stress Evaluations", to evaluate the patient's physiological responses (ANS), to stress. Typically, in such evaluations, the therapist attaches sensors (electrodes and other devices) to the client. These sensors monitor physiological responses such as heart rate, heart-rate variability, sweating (skin conductance), muscle tension, breathing rate/depth, brainwaves (EEG), and peripheral vasodilation/ constriction (finger temperature). The patients are then subjected to a mild laboratory stress (e.g., a mathematical task or silent recall of a stressful event). The patient is alternatively given tasks meant to make them relax or tense, in order to plot his or her ability to shift from stress responses (sympathetic) to relaxation (parasympathetic) as indicated by the physiological indices.

The psychophysiological assessments were initially formulated in the context of behaviour therapy, but they are equally applicable in the context of psychodynamic therapy, Cognitive Behaviour Therapy, humanistic therapies, or integrative psychotherapy.

\section{Biofeedback therapy}

Autonomic Nervous System processes are considered to be unconscious and involuntary. The laboratory work of psychologist Neal Miller [37] provided early evidence that laboratory animals, could be trained to control processes often thought to be involuntary, such as increasing or decreasing heart rate. In an impressive study, Basmajian [38] showed that a person could be trained to control a single motor unit in a muscle. His work has been very influential in muscle rehabilitation.

These early findings were counter-intuitive. They demonstrated that physiological processes previously considered as involuntary, could be brought under voluntary control with the help of mechanical devices. Indeed, even without the mechanical devices, people can acquire a measure of control over their autonomic processes by performing relaxation and breathing exercise. Finally, people often seek to modulate their own Autonomic Nervous System by engaging in activities like listening to music, going for a walk, meditating, or seeking pleasant company. Psychotherapists have the opportunity to meet these needs, and to provide the stress relief or relaxation which patients seek.

\section{Summary and Conclusion}

There is a large array of psychotherapy techniques, grouped into five main approaches. Rosenzweig [5], Frank [6] and others, proposed that no psychotherapy technique or approach is superior to others. The techniques are equally effective. Meta-analytic studies such as those by Luborsky and Luborsky [7] and Lambert [8] confirmed that the various psychotherapy approaches were equally effective. All this early work led to the view that psychotherapies are equally effective because of common factors present across the various techniques. Lambert [8] identified 
Citation: Mureriwa JFL (2017) Common Factors in Psychotherapy: The Autonomic Nervous System Final Common Pathway. Curr Adv Neurol Neurol Disord 2017: 1-12.

four clusters of factors, namely extra-therapeutic; relationship factors; placebo, hope and expectancy; and therapy technique, and he estimated that these factors contribute $40 \%, 30 \%, 15 \%$, and $15 \%$ respectively.

I proposed that these common factors are only an intermediate step for explaining the effectiveness of psychotherapy; and that the Autonomic Nervous System is the final common pathway. Inclusion of the assessment of the Autonomic Nervous System by psychologists appears to have great potential for helping to integrate the various psychotherapies.

\section{References}

1. Lebow JL (2012) Twenty-first psychotherapies: Contemporary Approaches to Theory and Practice. John Wiley and Sons.

2. Rogers CR (1957) The necessary and sufficient conditions of therapeutic personality change. Journal of Consulting Psychology 21: 95-103.

3. Department of Health (2001) Treatment choice in psychological therapies and counselling: Evidence based clinical practice guideline. Department of Health, United Kingdom.

4. Olatunji BO, Davis ML, Powers MB, Smits JA (2013) Cognitive-behavioral therapy for obsessive-compulsive disorder: A meta-analysis of treatment outcome and moderators. J Psychiatr Res 47: 33-41.

5. Rosenzweig $S$ (1936) Some implicit common factors in diverse methods of psychotherapy. American Journal of Orthopsychiatry 6: 412-415.

6. Frank JD (1974) Persuasion and healing: a comparative study of psychotherapy. (Rev. edn), Shocken books, New York, USA. Pg no: 1-378.

7. Luborsky L, Singer B, Luborsky L (1975) Is It True That "Everyone Has Won And All Must Have Prizes?" Arch Gen Psychiatry 32: 9951008.

8. Lambert MJ (1992) Psychotherapy Outcome Research: Implications for Integrative and Eclectic Therapists. In: Norcross JC, Goldfried MR (eds.). Handbook of psychotherapy integration. Basic Books, New York, USA. Pg no. 94-129.

9. Wampold BE (2015) How important are the common factors in psychotherapy? An update. World Psychiatry 14: 270-277.

10. Phelps EA (2004) Human emotion and memory: interactions of the amygdala and hippocampal complex. Curr Opin Neurobiol 14: 198202.

11. Soudry $Y$, Lemogne C, Malinvaud D, Consoli SM, Bonfils P (2011) Olfactory system and emotion: common substrates. Eur Ann Otorhinolaryngol Head Neck Dis 128: 18-23.

12. Olds J, Milner P (1954) Positive reinforcement produced by electrical stimulation of septal area and other regions of rat brain. J Comp Physiol Psychol 47: 419-427.

13. Freud S (1950) Project for a scientific psychology (1950). In: Strachey J (ed.). Standard Edition of the Complete Psychological Works of Sigmund Feud. Hogarth Press, London, UK. Pg no: 295-397.

14. Luria AR (1973) The working brain: An introduction to neuropsychology. Penguin Books, London, United Kingdom. Pg no: 146.
15. Raichle ME (2010) Twin views of brain function. Trends Cogn Sci 14: $180-190$.

16. Etkin A, Pittenger C, Polan HJ, Kandel ER (2005) Toward a Neurobiology of Psychotherapy: Basic Science and Clinical Applications. The Journal of Neuropsychiatry and Clinical Neurosciences 17:145158.

17. Di Pellegrino G, Fadiga L, Fogassi L, Gallese V, Rizzolatti G (1992) Understanding motor events: a neurophysiological study. Experimental Brain Research 91: 176-180.

18. Rizzolatti G, Craighero L (2004) The mirror-neuron system. Annual Review of Neuroscience 27: 169-192

19. Silani G, Lamm C, Ruff CC, Singer T (2013) Right supramarginal gyrus is crucial to overcome emotional egocentricity bias in social judgments. Journal of Neuroscience 33: 15466-15476.

20. Liggan DY, Kay J (1999) Some neurobiological aspects of psychotherapy: A Review. Journal of Psychotherapy Practice and Research 8: 103-114.

21. Brooks SJ (2015) A systematic review of the neural bases of psychotherapy for anxiety and related disorders. Dialogues Clin Neurosci 17: 261-279.

22. Boccia M, Piccardi L, Guariglia P (2016) How treatment affects the brain: meta-analysis evidence of neural substrates underpinning drug therapy and psychotherapy in major depression. Brain Imaging and Behavior 10: 619-627.

23. Kalsi N, Altavilla D, Tambelli R, Aceto P, Trentini C, et al. (2017) Neural Correlates of Outcome of the Psychotherapy Compared to Antidepressant Therapy in Anxiety and Depression Disorders: A Meta-Analysis. Frontiers in Psychology 8: 927.

24. Levenson RW (2014) The Autonomic Nervous System and Emotion. Emotion Review 6: 100-112.

25. Selye H (1983) The stress concept: past, present, and future. In: Cooper CL (ed.). Stress Research. John Wiley and Sons, New York, USA. Pg no: 1-20.

26. Lamm C, Majdandzic J (2015) The role of shared neural activations, mirror neurons, and morality in empathy--a critical comment. Neuroscience Research 90: 15-24.

27. Lockwood PL (2016) The anatomy of empathy: Vicarious experience and disorders of social cognition. Behavioural Brain Research 311: $255-266$.

28. Esch T, Stefano GB (2005) The neurobiology of love. Neuro Endocrinol Lett 26: 175-192.

29. Beck AT, Alford BA (1972) Depression Causes and treatment. (2ndedn), University of Pennsylvania Press Philadelphia, PA, USA.

30. Ellis A (1957) Rational Psychotherapy and Individual Psychology. Journal of Individual Psychology 13: 38-44.

31. Goldapple K, Segal Z, Garson C, Lau M, Bieling P, et al. (2004) Modulation of cortical-limbic pathways in major depression: Treatment-Specific Effects of Cognitive Behaviour Therapy. Arch Gen Psychiatry 61: 34-41.

32. Yoshimura S, Okamoto Y, Onoda K, Matsunaga M, Okada G, et al. (2014) Cognitive behavioral therapy for depression changes medial prefrontal and ventral anterior cingulate cortex activity associated with self-referential processing. Soc Cogn Affect Neurosci 9: 487493. 

2017: 1-12.

33. Banks SJ, Eddy KT, Angstadt M, Nathan PJ, Phan KL (2007) Amygdala-frontal connectivity during emotion regulation. Soc Cogn Affect Neurosci 2: 303-312.

34. Salone A, Di Giacinto A, Lai C, De Berardis D, Lasevoli F, et al. (2016) The Interface between Neuroscience and Neuro-Psychoanalysis: Focus on Brain Connectivity. Front Hum Neurosci 10: 20.

35. Panksepp J, Solms M (2012) What is neuropsychoanalysis? Clinically relevant studies of the minded brain. Trends in Cognitive Science 16: 6-8.
36. Pally R (2001) A Primary Role for Nonverbal Communication in Psychoanalysis. Psychoanalytic Inquiry: A Topical Journal for Mental Health Professionals 21: 71-93.

37. Miller NE (1969) Learning of visceral glandular responses. Science 163: 434-445.

38. Basmajian JV, De Luca CJ (1967) Muscles alive: their functions revealed by electromyography. Williams and Wilkins, Baltimore, USA. 